\title{
Hyperbilirubinemia: Does it matter?
}

\author{
Lajos Okolicsanyi MD, Giulia Martina Cavestro MD, Claudia Guatti-Zuliani MD
}

\begin{abstract}
L Okolicsanyi, GM Cavestro, C Guatti-Zuliani. Hyperbilirubinemia: Does it matter? Can J Gastroenterol 1999;13(8): 663-668. Serum bilirubin concentrations are increased in several hematological and hepatic disorders; however, hyperbilirubinemia, often of familial origin, may occur without overt signs of hemolysis or evident liver disease. The authors review briefly the main steps of hepatic bilirubin metabolism, then discuss the pathogenetic mechanisms of the different forms of familial hyperbilirubinemia. The knowledge of these conditions is increasingly important because orthotopic liver transplantation may be a therapeutic choice for some severe forms. Furthermore, early diagnosis is necessary to avoid unnecessary medical investigations for the otherwise relatively common, benign unconjugated hyperbilirubinemia. Finally, individuals with unmasked defective bilirubin handling may be potential liver donors; thus, unexplained jaundice occurring after orthotopic liver transplantation may be related to this disorder.
\end{abstract}

Key Words: Bilirubin; Hyperbilirubinemia; Liver disease; Orthoptic liver transplantation

\section{L'hyperbilirubinémie a-t-elle de l'importance?}

RÉSUMÉ : Plusieurs maladies hématologiques et hépatiques s'accompagnent d'élévations des concentrations de bilirubine sérique. En revanche, l'hyperbilirubinémie, souvent d'origine familiale, peut survenir sans signes évidents d'hémolyse ou de maladie hépatique. Les auteurs passent brièvement en revue les principales étapes du métabolisme de la bilirubine hépatique, puis énumèrent les mécanismes pathogènes des différentes formes d'hyperbilirubinémie familiale. La connaissance de l'existence de ces maladies est de plus en plus importante en raison du fait que la transplantation hépatique orthotopique pourrait être un choix thérapeutique envisageable dans plusieurs formes graves de la maladie. De plus, le diagnostic doit être posé sans délai si l'on veut éviter des analyses médicales superflues pour une hyperbilirubinémie non compliquée, bénigne et par ailleurs, relativement courante. En dernier lieu, les personnes qui souffrent d'un trouble du métabolisme de la bilirubine encore non démasqué pourraient devenir des donneurs de foie potentiels, donc, la jaunisse inexpliquée qui survient après une transplantation hépatique orthotopique pourrait être due à cette maladie passée inaperçue chez les donneurs.
$\mathrm{U}$ nconjugated bilirubin is present in small amounts in normal serum; it represents a balance between production and hepatic clearance of the pigment. Serum bilirubin concentrations are increased in several hematological and hepatic disorders; thus, increased bilirubin production or impaired hepatic handling manifests as hyperbilirubinemia. Since the first observation of Gilbert and Lerreboulet (1) at the beginning of this century, it has been known that mild, unconjugated hyperbilirubinemia without manifest hemolysis or evident liver disease is a relatively common condition, often of familial origin; since then, several other hyperbilirubinemia syndromes have been described (2).

Familial hyperbilirubinemia syndromes are selective dis-
TABLE 1

Familial hyperbilirubinemias

Type of hyperbilirubinemia

Unconjugated

Conjugated

Crigler-Najjar syndrome types I and II Dubin-Johnson syndrome

Gilbert's syndrome

Rotor syndrome

orders of bilirubin metabolism, resulting in the accumulation of pigment in the blood (Table 1). The most common form of these disorders is unconjugated hyperbilirubinemia,

This mini-review was prepared from a presentation made at the World Congress of Gastroenterology, September 6 to 11, 1998 , Vienna, Austria

Correspondence and reprints: Prof Lajos Okolicsanyi, Cattedra di Gastroenterologia, Istituto di Semeiotica Medica, University of Parma,

Via Gramsci, 14, 43100 Parma, Italy. Telephone +39-521-991772, fax +39-521-291582, e-mail okolajos@ipruniv.cce.unipr.it

Received for publication March 8, 1999. Accepted March 23, 1999 


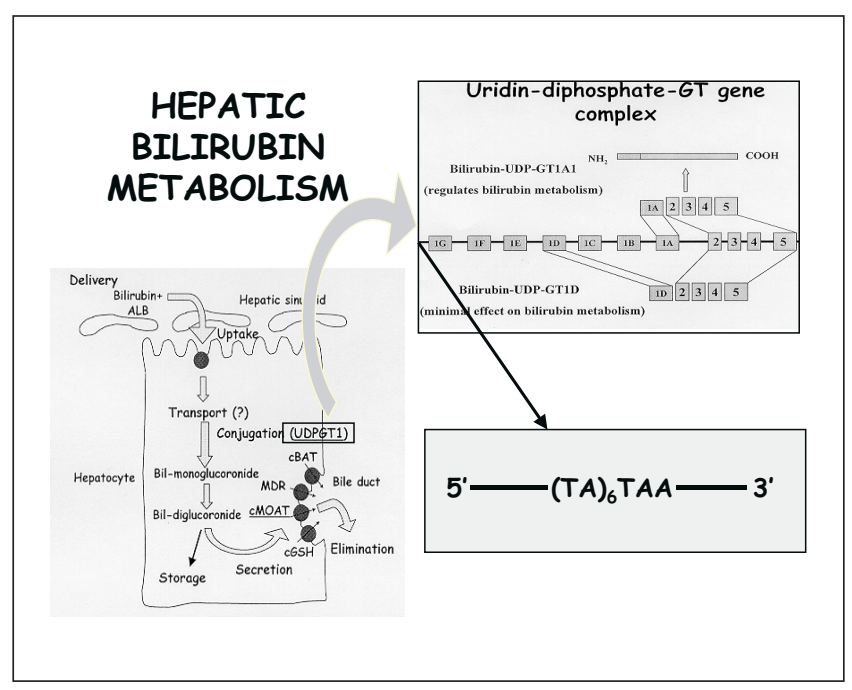

Figure 1) Metabolism of hepatic bilirubin. ALB Serum albumin; cBAT canalicular bile acid transporter; cMOAT Canalicular multiorganic anion transporter; GT Glucuronosyl transferase; MDR Multidrug resistant glycoprotein

which is found in $5 \%$ to $10 \%$ or more of Western populations. Clinical forms vary from this mild form of hyperbilirubinemia, also called Gilbert's syndrome, to severe Crigler-Najjar syndrome type I, where kernicterus and severe brain damage are frequent from early days of life and phenobarbital treatment is ineffective.

Conjugated hyperbilirubinemia syndromes were discovered in the late 1940s. They are very rare conditions; mild jaundice is present without other relevant clinical signs and the prognosis is excellent.

In the past decade, relevant progress has been made regarding the pathogenetic mechanisms and management of these conditions. In particular, orthotopic liver transplantation (OLTx) may be a therapeutic choice for some severe forms. Recent observations of otherwise unexplained jaundice occurring after OLTx indicated that hyperbilirubinemia may be related to defective bilirubin handling in the donor liver (3-5). Thus, the knowledge and early diagnosis of hyperbilirubinemia syndromes are increasingly important in the common clinical practice.

This review discusses the most relevant points of the above mentioned issues.

\section{HEPATIC BILIRUBIN METABOLISM}

Figure 1 shows the main steps of hepatic bilirubin metabolism. Unconjugated bilirubin is produced by catabolism of heme, principally in the reticuloendothelial system in the spleen. Unconjugated bilirubin is then delivered to the liver; in the blood it is tightly bound to albumin. When it reaches the sinusoidal surface of the liver cell, it is actively taken up by a carrier-mediated process. Once in the hepatocyte, it is bound and stored by protein structures, also called ligandins, and then transported to the microsomes of the smooth endoplasmic reticulum, where it is conjugated principally with one and subsequently with another molecule of glucuronic acid by forming mono- and diglucuronides of bilirubin. This process is catalyzed by the microsomal enzyme uridine diphosphoglucuronate-glucuronosyltransferase (UDP-GT); thus, the bilirubin molecule becomes soluble in water and can be secreted into the biliary tree, through a transportermediated process (canalicular multispecific organic anion transporter [cMOAT]).

Hyperbilirubinemia or jaundice may occur depending on which of the above steps is impaired.

The UDP-GT gene complex: Since the early 1970s, it has been known that UDP-GT has several isoforms (6). The large arrow in Figure 1 shows schematically what is known today about UDP-GT. It is located in region q37 (the long arm) of chromosome 2.

It has been clearly established that at least $10 \mathrm{mRNAs}$ are derived from this gene, each encoding a different isoform of UDP-GT. The 246 amino acid long carboxy terminal region (exons 2, 3, 4 and 5) is identical for all of UDP-GT isoforms. The 285 amino acid residue long amino terminal region is unique for each isoform (exons $1 \mathrm{~A}$ to $1 \mathrm{G}$ ). Exons $1 \mathrm{~A}$ and $1 \mathrm{D}$ encode the substrate specific amino termini of the two bilirubin UDP-GT isoforms identified in humans: bilirubin UDP-GT1A1 and bilirubin UDP-GT1D (less than 0.1\%). Only bilirubin UDP-GT1A contributes substantially to bilirubin glucuronidation (7).

The black narrow arrow in Figure 1 indicates the promoter TATAA box. This element is located in the promoter region of the gene and is involved in directing RNA polymerase II and transcription factor 2D to begin transcribing approximately 30 base pairs downstream in the mammalian system. In physiological conditions it is composed of six thymidine-adenine repeats: $\left(\mathrm{TA}_{6}\right) \mathrm{TAA}(8)$.

TABLE 2

Genetic variations in familial hyperbilirubinemias

$$
\text { UDP-GT complex }
$$

CMOAT

Crigler-Najjar syndrome type I Crigler-Najjar syndrome type II

Premature stop codon Missense mutations

Mutations at the splice donor site in intronic region
Insertion mutation of the TATAA element

CMOAT Canalicular multiorganic anion transporter; UDP-GT Diphosphoglucuronate-glucuronosyltransferase 


\section{GENETIC VARIATIONS IN FAMILIAL HYPERBILIRUBINEMIAS}

Table 2 summarizes the known genetic variations in familial hyperbilirubinemias.

Crigler-Najjar syndrome type I: Bosma et al (9) first demonstrated that Crigler-Najjar syndrome type I is related to a completely absent glucuronosyl transferase (GT) activity, which is due to several mutations of the enzyme gene complex. They showed that mutations in the premature stop codon consist of exons and mutations at the splice donor site in the intronic region, resulting in the expression of a truncated protein, which completely inactivates the enzyme. Homozygotes of mutated genes have Crigler-Najjar syndrome type I - these patients are unable to form glucuroconjugates of bilirubin. Consequently, very high concentrations of unconjugated bilirubin in serum are detected, which leads often, in the early days of life, to kernicterus and irreversible damage of the central nervous system (CNS).

Management of Crigler-Najjar syndrome type I: As far as the management of this severe form of hyperbilirbinemia is concerned, it is well established that phototherapy, given on a regular basis, at least every $12 \mathrm{~h}$ daily, is able to reduce unconjugated hyperbilirubinemia through the production of harmless, water-soluble end products of bilirubin, which can be easily eliminated into the urine. In these patients, this therapy is used favourably from the early days of life. It must be emphasized, however, that compliance of young patients is not easy to obtain; it also seems that this therapy is less efficacious later on.

The only effective treatment of this disease is OLTx, which assures long term survival of these patients. OLTx is mandatory when phototherapy is not guaranteed or is not efficient, or when early signs of CNS damage appear.

In the world registry of Crigler-Najjar syndrome type I patients in 1996, 21 of 57 patients underwent OLTx and were in good physical condition (10). Better results were obtained when OLTx was performed early in the disease progression.

An alternative to OLTx may be liver cell transplantation (11). This revolutionary method has been recently applied in one patient with Crigler-Najjar syndrome type I (12). The technique is quite simple: through a single intraportal infusion, approximately $5 \%$ of normal liver cell mass is given. Fox et al (12) reported during a nine-month follow-up period a stable expression of GT activity, with consistent reduction of serum bilirubin levels.

While these data are very encouraging, because of the simplicity of the method, there are several unresolved issues regarding the definition of the donor liver cell mass; further questions arise about the utility of repeated liver cell infusions and whether these can express a major immunogenicity, which is considered to be minimal after a single intraportal infusion. The availibility of hepatocyte donor liver is a limitation, as with whole liver donors.

Crigler-Najjar syndrome type II: Bosma and co-workers (13) showed that, in patients with Crigler-Najjar syndrome type II, the mutations are missense mutations (eg, Gly-Arg) of the UDP-GT complex and insertion mutations of the TA-

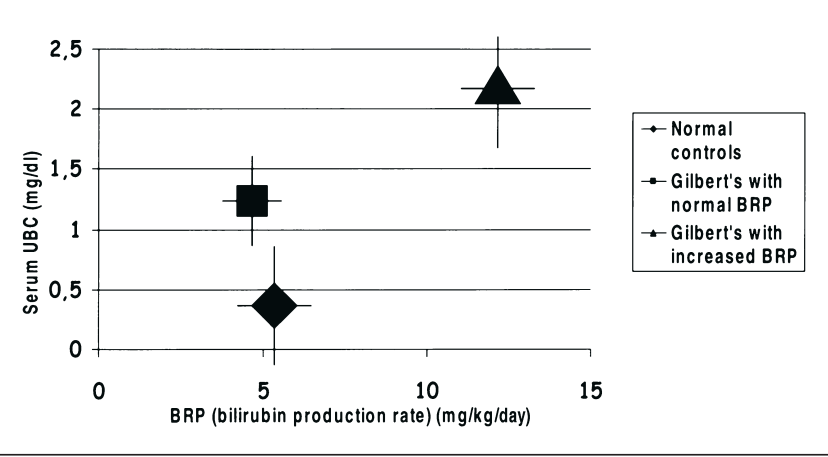

Figure 2) Serum unconjugated bilirubin concentration (UBC) as a function of the bilirubin production rate (BRP). Data from reference 18

TAA element. This is a heterozygote mutation; residual enzyme activity is derived from the other allele. As a consequence, some GT enzyme activity is present in liver microsomes; thus, bilirubin is partially conjugated with glucuronic acid to form monoglucuronides of the pigment. These pigment conjugates are detectable in the bile of these patients and may be relevant for the differential diagnosis from type I disease, where bilirubin conjugates are absent. Thus, serum bilirubin concentrations are usually high - the maximal levels reach about 20 to $25 \mathrm{mg} / 100 \mathrm{~mL}$ of bilirubin. Damage of the CNS is rare, and enzyme inducers (sodium phenobarbitone) may help in lowering bilirubin and jaundice.

These patients need reassurance about the favourable course of their jaundice and relatively good prognosis.

Gilbert's syndrome: Bosma et al (8) showed that subjects with Gilbert's syndrome have a genetic defect in the promoter region of the UDP-GT gene: in particular, instead of a TATAA element with six TA repeats, there are two extra bases of thymidine-adenine. The UDP-GT gene complex is unaltered: the nucleotide sequences of all five exons encoding the gene for UDP-GT1 and all intron-exon junctions are normal, indicating that the condition is not caused by structural mutations.

The same authors (8) observed that patients with Gilbert's syndrome are homozygous for the TATAA box abnormality; however, this abnormality is not enough to reveal hyperbilirubinemia and subicterus. In their studies, homozygous expression of the abnormal promoter element occurred in about $40 \%$ of normal controls, suggesting that Gilbert's syndrome is a heterogeneous condition that consists of a combination of this genetic abnormality and one or more additional factors.

The heterogeneity of Gilbert's syndrome has been known for a long time. While there is unanimous agreeement that these individuals have reduced UDP-GT activity in their liver $(6,14,15)$, the hepatic enzyme activity does not always correlate with serum bilirubin concentrations (14). Furthermore, other studies indicated that there was no correlation between lowering of serum bilirubin levels and liver microsomal UDP-GT activity when enzyme inducers such as sodium phenobarbitone were given (16). 
TABLE 3

Familial conjugated hyperbilirubinemias

\begin{tabular}{|c|c|c|}
\hline & $\begin{array}{c}\text { Dubin-Johnson } \\
\text { syndrome }\end{array}$ & $\begin{array}{c}\text { Rotor } \\
\text { syndrome }\end{array}$ \\
\hline Heredity & Autosomal recessive & Autosomal recessive \\
\hline Transporter defect & CMOAT & Unknown \\
\hline $\begin{array}{l}\text { Bromo-sulphonphthalein } \\
\text { clearance }\end{array}$ & late rise & delayed uptake \\
\hline Transport maximum & $\downarrow \downarrow$ & $\downarrow$ \\
\hline $\begin{array}{l}\text { Storage } \\
{ }^{99 m} \text { Tc-HIDA }\end{array}$ & Normal & $\downarrow \downarrow$ \\
\hline Visualization liver & Normal & Absent \\
\hline Biliary tree & Absent & Absent \\
\hline Oral cholecystography & Gallbladder not seen & Normal \\
\hline Liver pigment & Brown/black & None \\
\hline Coproporphyrin total & Normal & ヤ个 \\
\hline Coproprophyrin I & $\uparrow$ & ヘト \\
\hline
\end{tabular}

$\boldsymbol{\uparrow}$ Increase; $\downarrow$ Decrease. CMOAT canalicular multispecific organic anion transporter; ${ }^{99 m} T_{C}-H I D A{ }^{99 m} T_{C}$-imino-diacetic acid

That additional factors are required to manifest hyperbilirubinemia is confirmed by previous kinetic studies performed with ${ }^{14}$ carbon-labelled bilirubin (17) or with cristalline bilirubin (18). In these studies, patients with Gilbert's syndrome were divided into two groups according to their calculated bilirubin production rate - one group with normal daily bilirubin production and a second group with an increased bilirubin turnover rate comprising about $40 \%$ of the patients with Gilbert's syndrome (Figure 2). Furthermore, these findings agree with those of Powell and co-workers (19), who found a reduced erythrocyte survival rate in about $45 \%$ to $50 \%$ of patients with unconjugated hyperbilirubinemia. Finally, reduced caloric intake for a 24 to $48 \mathrm{~h}$ period significantly increases serum bilirubin concentrations in individuals with Gilbert's syndrome, in whom the increase at the end of the $48 \mathrm{~h}$ fasting period reaches more than $200 \%$ of basal values (20). The mechanism of this phenomenon is not definitely known; an enhanced liver heme-oxygenase activity may stimulate the intrahepatic bilirubin production rate (21). Intestinal absorption of unconjugated bilirubin may also contribute to an endogenous bilirubin load during fasting (22).

Thus, it seems evident that increased bilirubin production due to several factors may be relevant in the clinical manifestation of hyperbilirubinemia in this heterogeneous condition.

\section{FAMILIAL CONJUGATED HYPERBILIRUBINEMIAS}

Table 3 summarizes the mean characteristics of familial conjugated hyperbilirubinemia.

Dubin-Johnson syndrome: Typical phenotypic and diagnostic features of Dubin-Johnson syndrome are highly similar to those of the transport-deficient rat, a mutant of the Wistar rat strain, which is defective in the cMOAT. Pau-

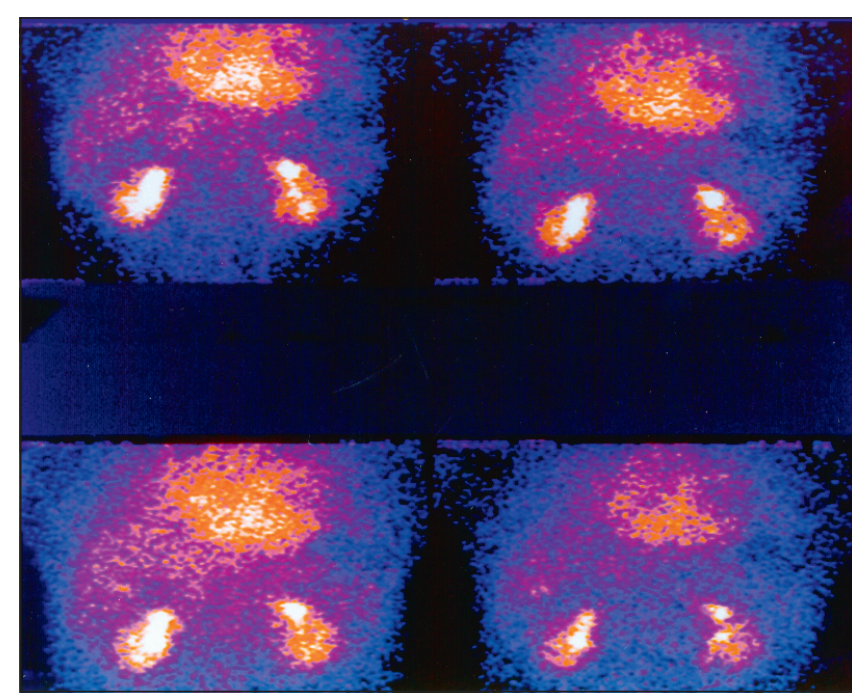

Figure 3) Radioscintigraphy with ${ }^{99 m}$ Tc-Imino-diacetic acid (HIDA) showing severely impared hepatobiliary clearance. The radionuclide is highly concentrated in the heart and both kidneys in subsequent time periods

lusma and co-workers (23) isolated the human cMOAT from fibroblasts of a patient with Dubin-Johnson syndrome and found mutations in the corresponding cDNA (Figure 1). Wada et al (24) showed that missense mutations and deletion of several nucleotides were evident in the cDNA of four Dubin-Johnson patients (see also Table 2).

The hepatic handling of bromo-sulphonphthalein (BSP) is altered in Dubin-Johnson syndrome. Following intravenous injection of this substance, a late rise of pigment concentration is seen in blood, which reaches its highest levels $3 \mathrm{~h}$ after the intravenous administration. Needle liver biopsy taken from the liver of these patients shows a characteristic pigmentation mostly near the bile canaliculi. There is still controversy about the composition of this pigment (perhaps lipofuscin or melanin-like) (25). Furthermore, the relationship between this intracellular pigment deposition and the observed transporter defect in these individuals is unclear.

Rotor syndrome: Familial conjugated hyperbilirubinemias also include one other rare form, originally described by Rotor et al (26). Serum bilirubin levels are usually high, between 3 to $5 \mathrm{mg} / 100 \mathrm{~mL}$ with a prevalent conjugated fraction. Similar to Dubin-Johnson syndrome, this is a congenital jaundice with autosomal recessive heredity. The transporter defect is not yet characterized. BSP clearance is delayed during the first 45 mins, without the late rise reported in Dubin-Johnson syndrome; however, storage of the pigment is significantly decreased, which may be related to a transporter defect. The hypothesis of a transporter defect is further confirmed by studies with ${ }^{99 \mathrm{~m}} \mathrm{Tc}$-Imino-diacetic acid (HIDA) radioscan performed in these patients. Figure 3 was obtained from one patient currently under investigation and it shows an absent visualization of the liver, after an intravenous administration of the radiocolloide, while the heart and both kidneys are intensely revealed by scanning.

Finally, in both conjugated hyperbilirubinemias the me- 
tabolism of coproporphyrin, which originates from heme metabolism, is altered (Table 3) (27).

Further studies are needed to define the nature and characteristics of the transporter defect.

\section{DIFFERENTIAL DIAGNOSIS OF HYPERBILIRUBINEMIAS}

Some practical criteria may help physicians and specialists in the differential diagnosis of hyperbilirubinemia syndromes.

Diagnosis is essentially performed by exclusion. History, physical examination, routine liver function tests and total serum bile acids should be performed and, when normal, familial hyperbilirubinemia should be suspected.

To differentiate familial hyperbilirubinemias further, when the unconjugated fraction is prevalent, hemolytic syndromes should be investigated and excluded. When hemolysis is not confirmed, serum bilirubin concentrations should be determined at least three times, in one-month intervals, because of the possible fluctuations of serum bilirubin levels. When hyperbilirubinemia is confirmed, Gilbert's hyperbilirubinemia should be suspected. In some cases, when a so called 'positive' diagnosis is requested by the patient, the simple, reduced caloric intake test should be proposed (28). There is no need for medical treatment or follow-up. Patients and their family members need reassurance about the benignity of this condition, which can favourably be influenced, when requested (most frequently for cosmetic reasons), by enzyme inducers.

In rare cases, when deep jaundice is seen and serum bilirubin concentrations range from 6 to $25 \mathrm{mg} / 100 \mathrm{~mL}$ of bilirubin, without clinical signs of damage to the CNS, Crigler-Najjar syndrome type II should be suspected. In the more severe form, with extreme serum bilirubin values, Crigler-Najjar syndrome type I should be suspected. To define the diagnosis further, conjugates of bilirubin in the bile and in the serum should be determined. Both of these conditions should then be handled as previously described in detail in this article.

Familial conjugated hyperbilirubinemias are rare conditions. The differential diagnosis between Dubin-Johnson

\section{REFERENCES}

1. Gilbert A, Lereboullet P. La cholemie simple familiale. Semaine Medicale 1901;31:241-3.

2. Okolicsanyi L, ed. Familial Hyperbilirubinemia. New York: Wiley \& Sons, 1980.

3. Arnold J, Otto G, Kraus T, Kommerell B, Theilmann L. Gilbert's syndrome: a possible cause of hyperbilirubinemia after orthotopic liver transplantation. J Hepatol 1992;14:404.

4. Lachaux A, Aboufadel A, Chambon M, et al. Gilbert's syndrome: a possible cause of hyperbilirubinemia after orthotopic liver transplantation. Transplant Proc 1996;28:2846.

5. Jansen PLM, Bosma PJ, Bakker C, Lems SPM, Sloff MJH, Haagsma EB. Persistent unconjugated hyperbilirubinemia after liver transplantation due to an abnormal bilirubin UDP.

glucuronosyltransferase gene promotor sequence in the donor J Hepatol 1997;27:1-5.

6. Okolicsanyi L, Frei J, Magnenat P, Naccarato R. Multiplicity and specificity of UDP-glucuronyl transferase. Enzyme 1971;12:658-73.

7. Bosma PJ, Seppen J, Goldhoorn B, et al. Bilirubin UDP and Rotor syndrome has already been discussed above. In our experience, a ${ }^{99} \mathrm{Tm}$-HIDA scan should be sufficient to differentiate the two forms; thus, liver biopsy may be avoided.

Reassuring patients about their benign condition is essential because serum bilirubin levels often reach $5 \mathrm{mg} / 100 \mathrm{~mL}$ of bilirubin, or even more, and cutaneous jaundice may be particularly evident, which can induce cosmetic problems, particularly in women.

\section{HYPERBILIRUBINEMIA: DOES IT MATTER?}

The question arises whether unconjugated hyperbilirubinemia syndromes are of clinical importance. The answer is no in the vast majority of cases because the severe forms of Crigler-Najjar syndromes are rare. As already mentioned, there are no more than 60 patients registered worldwide.

Diagnosing hyperbilirubinemia in the mild unconjugated form of Gilbert's syndrome is important, however, to avoid further diagnostic procedures. Furthermore, the question arises whether latent or unmasked abnormality of the TATAA box in otherwise normal liver donors may be responsible for the prolonged hyperbilirubinemia seen in recipients. Suspicion of this event is essential because other more severe and relatively frequent pathological conditions, such as graft versus host disease, should be excluded.

In the scientific literature, a number of clinical reports have dealt with this issue $(3,4)$; the general conclusion is that individuals with previously known unconjugated hyperbilirubinemia should be favourably considered as potential liver donors (5).

\section{CONCLUSIONS}

Relevant progress has been made during the past decade by identifying the majority of transporter defects responsible for hyperbilirubinemia. However, a number of questions regarding these conditions remain unanswered: the defective transporter in Rotor syndrome is unknown; the nature, origin and significance of liver pigmentation in Dubin-Johnson syndrome must be defined; and further studies are needed to establish the heredity of the 'heterogeneous' Gilbert's syndrome.

glucuronosyltransferase 1 is the only relevant bilirubin glucuronidating isoform in man. J Biol Chem 1993;268:235-9.

8. Bosma PJ, Chowdhury JR, Bakker C, et al. The genetic basis of the reduced expression of bilirubin UDP-glucuronosyltransferase 1 in Gilbert's syndrome. N Engl J Med 1995;333:1171-5.

9. Bosma PJ, Chowdhury NR, Goldhoorn BG, et al. Sequence of exons and the flanking regions of human bilirubin UDP. glucuronosyltransferase gene complex and identification of a genetic mutation in a patient with Crigler-Najjar syndrome, type I. Hepatology 1992;15:941-7.

10. van der Veere CN, Sinaasappel M, McDonagh AF, et al. Current therapy for Crigler-Najjar syndrome type I: report of a world registry. Hepatology 1996;24:311-5.

11. Gupta S, Gorla GR, Irani AN. Hepatocyte transplantation: emerging insights into mechanisms of liver repopulation and their relevance to potential therapies. J Hepatol 1999;30:162-70.

12. Fox IJ, Chowdhury JR, Kaufman SS, et al. Treatment of the Crigler-Najjar syndrome type I with hepatocyte transplantation. N Engl J Med 1998;338:1422-6. 
13. Bosma PJ, Goldhoorn B, Oude Elferink RP, Sinaasappel M, Oostra BA, Jansen PL. A mutation in bilirubin uridine 5' diphosphate glucuronosyltransferase isoform 1 causing Crigler-Najjar syndrome type II. Gastroenterology 1993;105:216-220.

14. Black M, Billing BH. Hepatic bilirubin UDP-glucuronyl transferase activity in liver disease and Gilbert's syndrome. N Engl J Med 1969;280:1266-71.

15. Felsher BF, Craig JR, Carpio N. Hepatic bilirubin glucuronidation in Gilbert's syndrome. J Lab Clin Med 1973;81:829-37.

16. Fevery J, Van Steenbergen W, Sieg A, Muraca M. Pathophysiology of the hyperbilirubinemias. In: Tavoloni N, Berk PD, eds. Hepatic Transport and Bile Secretion: Physiology and Pathophysiology. New York: Raven Press, Ltd, 1993:637-47.

17. Berk PD, Bloomer JR, Howe RB, Berlin NI. Constitutional hepatic disfunction (Gilbert's syndrome). A new definition based on kinetic studies with unconjugated radiobilirubin. Am J Med 1970;83:296-305.

18. Okolicsanyi L, Ghidini O, Orlando R, et al. An evaluation of bilirubin kinetics with respect to the diagnosis of Gilbert's syndrome. Clin Sci Mol Med 1978:54:539-47.

19. Powell LW, Hemingway E, Billing BH, Sherlock S. Idiopathic unconjugated hyperbilirubinemia (Gilbert's syndrome). A study of 42 families. N Engl J Med 1967;23:1108-12.

20. Owens D, Sherlock S. Diagnosis of Gilbert's syndrome: Role of reduced caloric intake. Br Med J 1973;3:559-63.
21. Okolicsanyi L, Orlando R, Venuti M, et al. A modeling study of the effect of fasting on bilirubin kinetics in Gilbert's syndrome. Am J Physiol 1981;240:R266-71.

22. Kotal P, Vitek L, Fevery J. Fasting-related hyperbilirubinemia in rats: the effect of decreased intestinal motility. Gastroenterology 1996;111:217-23.

23. Paulusma C, Kool M, Bosma P, et al. A mutation in the human canalicular multispecific organic anion transporter gene causes the Dubin-Johnson syndrome. Hepatology 1997;25:1539-42.

24. Wada M, Toh S, Taniguchi K, et al. Mutations in the canalicular multispecific organic anion transporter (cMOAT) gene, a novel ABC transporter, in patients with hyperbilirubinemia II/ Dubin-Johnson syndrome. Hum Mol Gen 1998; 7:203-7.

25. Okolicsanyi L, Nassuato G, Strazzabosco M. Familial hyperbilirubinemias: clinical aspects. In: Tavoloni N, Berk PD, eds. Hepatic Transport and Bile Secretion: Physiology and Pathophysiology. New York: Raven Press, Ltd, 1993:649-64.

26. Rotor AB, Manahan L, Florentin A. Familial non-hemolytic jaundice with direct van den Bergh reaction. Acta Med Philipp 1948;5:37-49.

27. Wolkoff AW. Chronic conjugated hyperbilirubinemia: Dubin-Johnson and Rotor's syndromes. In: Okolicsanyi L, ed. Familial Hyperbilirubinemia. Chichester: Wiley \& Sons, 1980:221-34.

28. Okolicsanyi L, Fevery J, Billing B, et al. How should mild, isolated unconjugated hyperbilirubinemia be investigated? Semin Liver Dis 1983;3:36-41. 


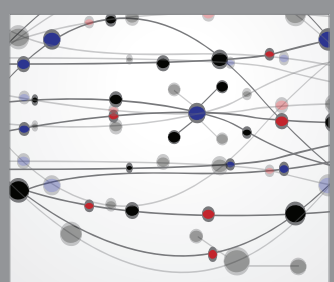

The Scientific World Journal
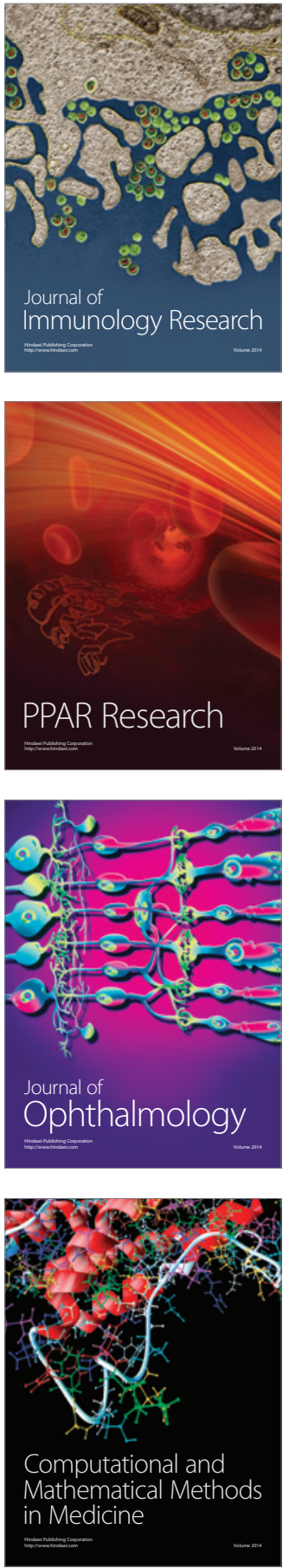

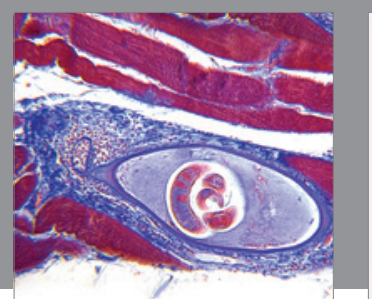

Gastroenterology Research and Practice

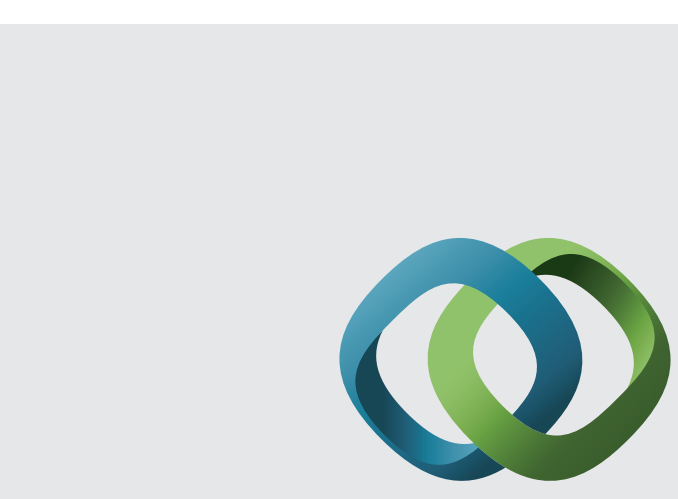

\section{Hindawi}

Submit your manuscripts at

http://www.hindawi.com
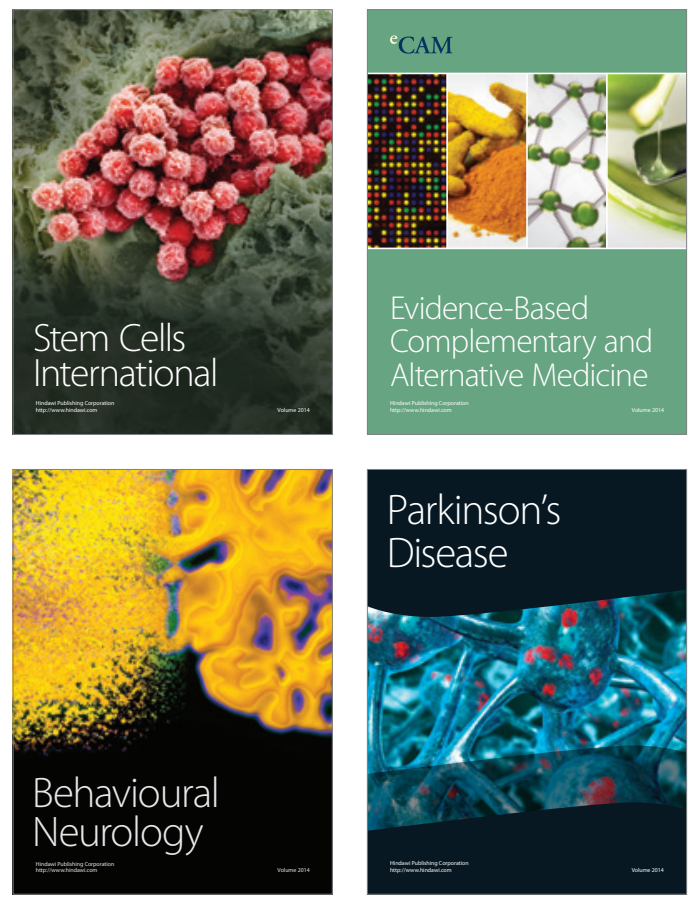
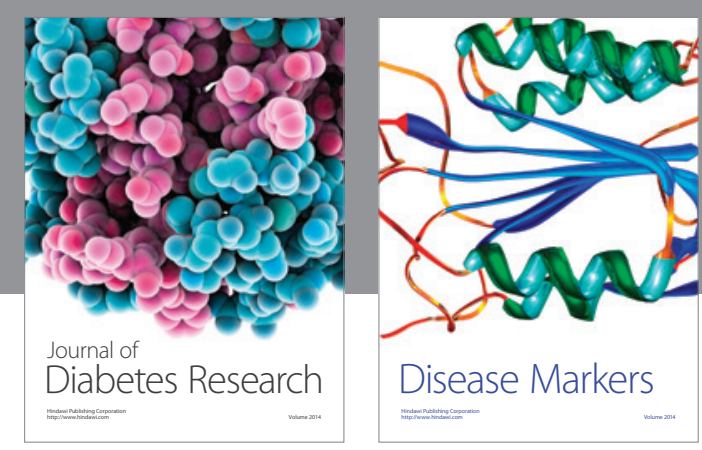

Disease Markers
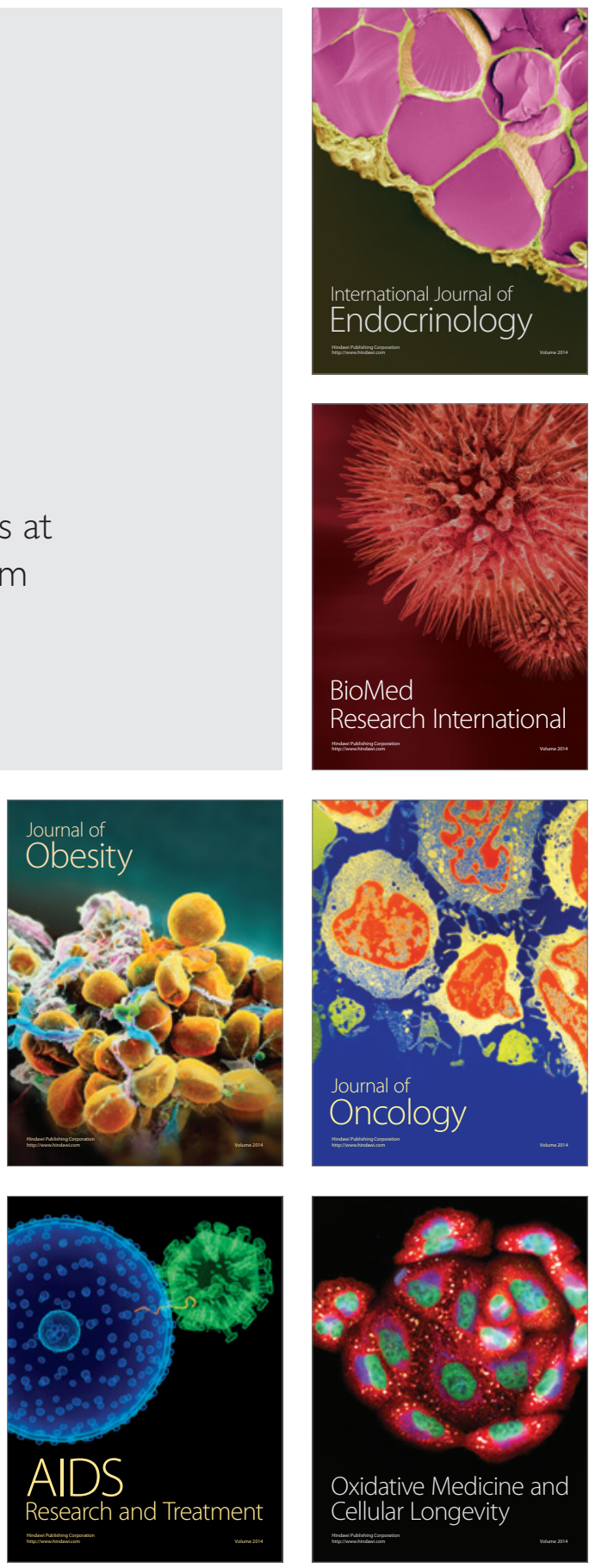